\title{
Are Fluorescent Silicon Nanoparticles Formed in a One-Pot Aqueous Synthesis?
}

\author{
Bohdan V. Oliinyk, ${ }^{* \dagger, \ddagger(1)}$ Dmytro Korytko, ${ }^{\dagger}$ Vladimir Lysenko, ${ }^{\S, \|}$ and Sergei Alekseev ${ }^{\dagger}$ \\ ${ }^{\dagger}$ Chemistry Department, Taras Shevchenko National University of Kyiv, Volodymyrska Street, 64, 01601 Kyiv, Ukraine \\ ${ }^{\ddagger}$ Institute of Analytical Sciences, UMR-5280, Claude Bernard University of Lyon, 5 rue de la Doua, 69100 Villeurbanne, France \\ ${ }^{\S}$ Lyon Institute of Nanotechnology, UMR-5270, INSA Lyon, 7 avenue Jean Capelle, 69621 Villeurbanne, France \\ "Light Matter Institute, UMR-5306, Claude Bernard University of Lyon, 2 rue Victor Grignard, 69622 Villeurbanne, France
}

Supporting Information

ABSTRACT: Critical analysis of the data reported by Zhong et al. (J. Am. Chem. Soc. 2013, 135 (22), 8350-8356) is carried out. In particular, one of the main results of Zhong et al. concerning the formation of photoluminescent silicon nanoparticles ( $\mathrm{Si} \mathrm{NPs}$ ) in an aqueous solution of (3aminopropyl)trimethoxysilane (APTMS) and trisodium citrate dihydrate $\left(\mathrm{Na}_{3} \mathrm{Cit}\right)$ under microwave heating is impugned. These results are reconsidered here because of what appear to be significant inaccuracies and misinterpretations that have been spread through a wide number of other subsequent publications.

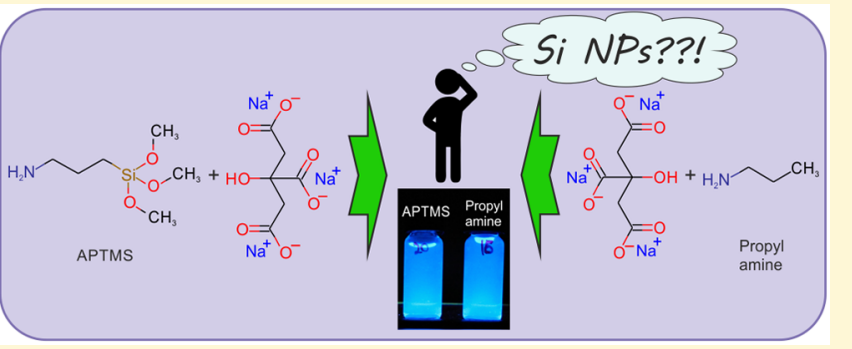

knowledge in the field of silicon chemistry, ${ }^{52-54}$ low temperature formation of crystalline $\mathrm{Si}^{0}$ nanoparticles (as reported by Zhong et al.) from the water solutions of alkoxysilanes seems very doubtful. Indeed, it remains entirely unclear which reactants in the reaction mixture are remotely capable of reducing a silicon atom bound to oxygen. Moreover, silicon nanoparticles of the claimed size are extremely difficult to passivate and would be very rapidly oxidized to $\mathrm{SiO}_{2}$ under the action of water. ${ }^{5}$ If the reported reduction of the $\mathrm{Si}-\mathrm{O}$ bonds by citrate were reproducible by other groups, the impact of this discovery would be much more important than just an easy and scalable method for preparation of Si NPs for biological applications. It would represent a new page of silicon chemistry that opens the door to the preparation of inexpensive silicon and silicon-based materials manufacturing. Thus, it deserves to be further investigated to avoid any incorrect speculation on that theme.

First of all, the TEM micrographs presented by Zhong et al. (Figure 1a) as well as a similar image from ref 17 show (i) a number of spherical particles without any evidence of crystallinity at a $5 \mathrm{~nm}$ scale and (ii) a single obviously crystalline particle at a $1 \mathrm{~nm}$ scale. However, if the lattice fringes are clearly visible at a $1 \mathrm{~nm}$ scale, they should be also visible at a $5 \mathrm{~nm}$ scale at least for a few particles having the correct orientation with respect to the incident electron beam (e.g., see Figure 1b). Furthermore, taking into account the

Received: March 16, 2019

Revised: July 2, 2019

Published: July 2, 2019 

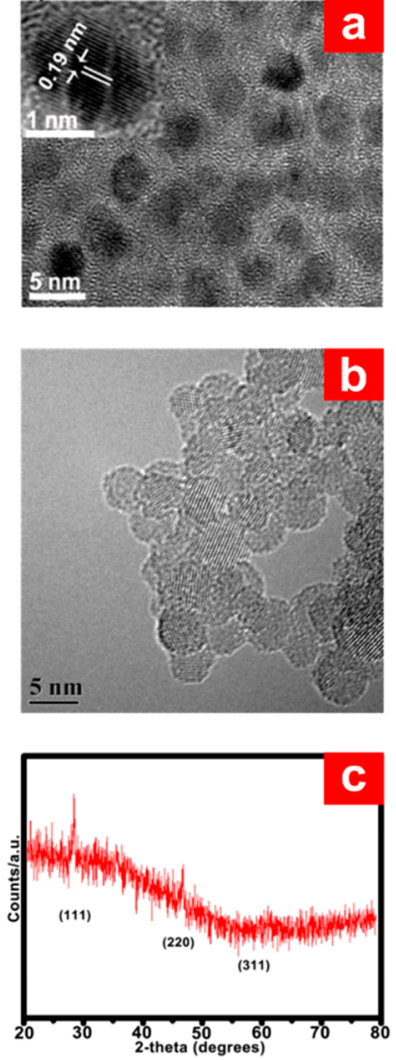

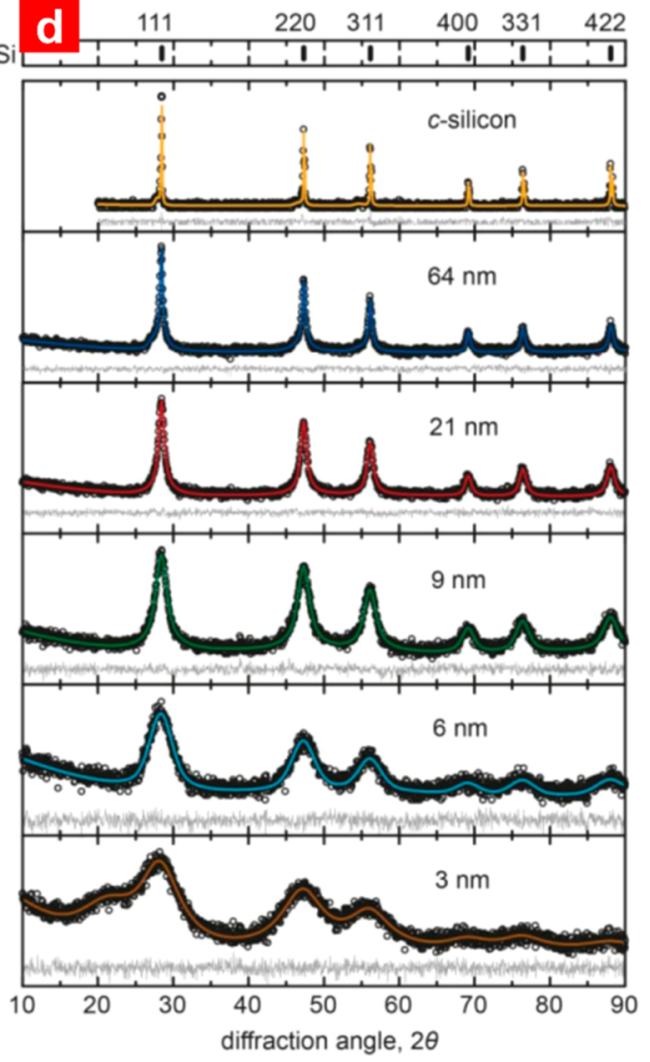

Figure 1. (a) HRTEM images of the $\mathrm{Na}_{3} \mathrm{Cit}+\mathrm{APTMS}$ reaction product. Reprinted with permission from ref 1 . Copyright 2013 American Chemical Society. (b) HRTEM images of plasma synthesis Si NPs. Reprinted with permission from ref 56. Copyright 2009 American Chemical Society. (c) Powder XRD patterns of the $\mathrm{Na}_{3} \mathrm{Cit}+$ APTMS reaction product. Reprinted with permission from ref 1 . Copyright 2013 American Chemical Society. (d) Powder XRD patterns of crystalline Si and H-terminated Si NPs of different sizes. Reprinted with permission from ref 57. Copyright 2019 American Chemical Society.

scale bar $(1 \mathrm{~nm})$ in Figure 1a, the lattice spacing cannot correspond to $0.19 \mathrm{~nm}$ as is indicated, but rather to $0.057 \mathrm{~nm}$, which seems doubtful for Si NPs.

An XRD pattern of the particles prepared by Zhong et al. (Figure 1c) differs significantly from typical XRD patterns of $\mathrm{Si}$ NPs (Figure 1d). Indeed, no characteristic broad peaks inherent to the nanoscale crystallites ${ }^{55}$ can be seen on Figure 1c. The narrow and barely visible peaks at $2 \theta=28$ and $47^{\circ}$ in Figure 1c can be related rather to traces of some crystalline admixtures (inorganic salts, for example), residual peaks from the "zero-background sample holder made of monocrystalline silicon plate" or other artifacts. Furthermore, no data regarding the $\mathrm{X}$-ray source is given in the original paper. Thus, the XRD data does not provide solid evidence of the formation of the $204 \mathrm{~nm}$ crystalline Si NPs.

Finally, according to the best practices of NP characterization, ${ }^{58}$ provision of XPS data is absolutely necessary. Indeed, it could shed light on the oxidation state of silicon atoms in the particles. However, no thorough XPS analysis was provided in this publication, and thus, the compositional identity of the NPs is still questionable.

In order to check the assumption expressed by Zhong et al. regarding the formation of $\mathrm{Si} \mathrm{NPs}$, the following control reactions between sodium citrate and organic amine (one containing silicon, APTMS, and one without silicon, $n$ propylamine) have been carried out.

The reaction conditions were chosen to be the closest to those by Zhong et al., as described here. In particular, $5 \mathrm{mmol}$ of amine was added to $10 \mathrm{~mL}$ of deionized water. Then, 5 mmol of trisodium citrate was added. In the case of $n$ $\mathrm{C}_{3} \mathrm{H}_{7} \mathrm{NH}_{2}, 15 \mathrm{mmol}$ of methanol was added to simulate the same conditions as in the case of APTMS, which hydrolyzes in water to produce methanol. At this point, the solutions were transferred into $25 \mathrm{~mL}$ PTFE-lined stainless steel autoclaves. The sealed autoclaves were heated to $180{ }^{\circ} \mathrm{C}$ in an electric oven and left for an additional $5 \mathrm{~h}$ at this temperature. The final solutions were centrifuged at $10000 \mathrm{rpm}$ for $5 \mathrm{~min}$, but no precipitate was observed to form, as had been reported.

Products of the reactions of $\mathrm{Na}_{3} \mathrm{Cit}$ with both Si-containing APTMS and Si-free $n-\mathrm{C}_{3} \mathrm{H}_{7} \mathrm{NH}_{2}$ appeared as yellowish (colorless upon dilution) clear solutions with bright blue photoluminescence (PL) under UV excitation (Figure 2a). Steady-state PL and absorption spectra were collected using an Edinburgh Instruments Ltd. FLS920 spectrometer with a Xe lamp (150W, Hamamatsu) as the excitation source. The PL, PL excitation, and optical absorbance spectra were found to be identical (Figure $2 b, c$ ), independent of the presence or absence of silicon in the organic amine. Furthermore, the general appearance and the spectral properties of the "Si NPs sol" described by Zhong et al. are also identical to those shown here in Figure 2.

In addition, to further confirm the similarity of the reaction products, time-resolved PL and PL photostability experiments were carried out. A picosecond pulsed laser EPL-375 $\left(\lambda_{\mathrm{em}}=\right.$ $377.2 \mathrm{~nm}, 76.4$ ps pulse width) was used as an excitation source for the time-resolved PL measurements. Figure 3a shows time-resolved PL of the both samples. The degree of the similarity between the two samples is obvious, and indeed 


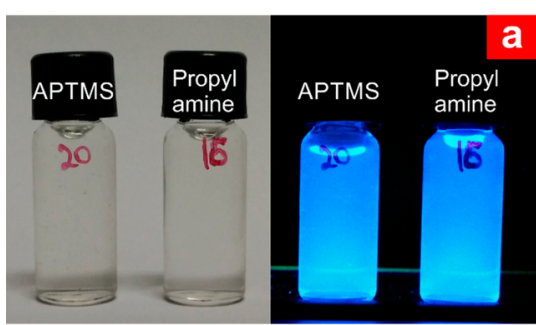

b
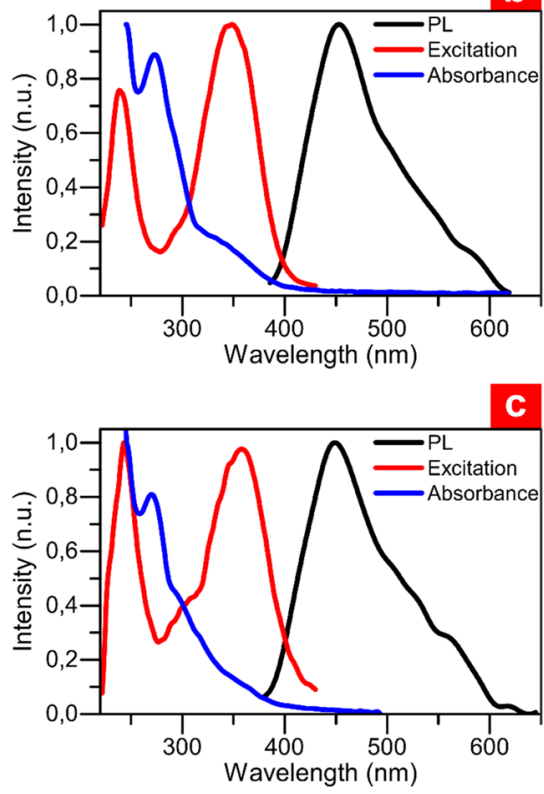

Figure 2. (a) Appearance of the reaction products under ambient light (left) and $365 \mathrm{~nm}$ irradiation (right). $\mathrm{PL}, \mathrm{PL}$ excitation, and absorbance spectra of (b) $\mathrm{Na}_{3} \mathrm{Cit}+n-\mathrm{C}_{3} \mathrm{H}_{7} \mathrm{NH}_{2}$ and (c) $\mathrm{Na}_{3} \mathrm{Cit}+$ APTMS reaction products $\left(\lambda_{\text {excitation }}=365 \mathrm{~nm}\right.$ and $\left.\lambda_{\text {emission }}=450 \mathrm{~nm}\right)$.
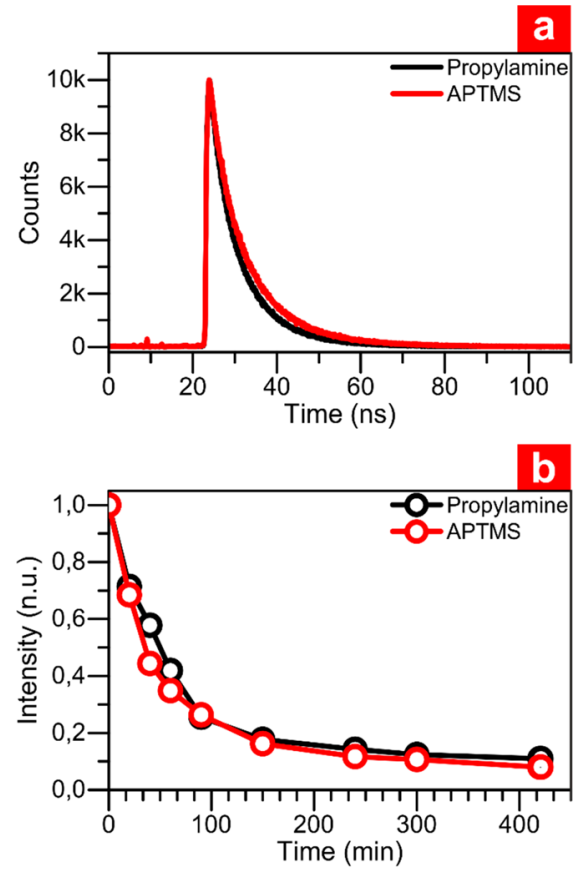

Figure 3. (a) Time-resolved fluorescence and (b) PL photostability of Si-containing (APTMS) and Si-free $\left(n-\mathrm{C}_{3} \mathrm{H}_{7} \mathrm{NH}_{2}\right)$ reaction products. fitting with a single exponent $\left(y=y_{0}+A \mathrm{e}^{-x / \tau}\right)$ yields close PL lifetimes: 7 and 8 ns for $n-\mathrm{C}_{3} \mathrm{H}_{7} \mathrm{NH}_{2}$ and APTMS derived samples, respectively. Such low and similar PL lifetimes suggests a common molecular nature of the luminescent species.

A $100 \mathrm{~W}$ Hg lamp (UVP, Blak-Ray B-100AP, 21,700 $\mu \mathrm{W} /$ $\mathrm{cm}^{2}$ at 2 in.) with a $365 \mathrm{~nm}$ bandpass filter was used for illumination of the samples to study their PL photostability. Aqueous solutions $(15 \mathrm{~mL})$ of both samples with similar PL intensities were mounted in the center of the lamp beam, with a distance of $5 \mathrm{~cm}$ from the lamp filter (effective radiated crosssections of the tubes were $\sim 15 \mathrm{~cm}^{2}$ ). Samples were collected, and their PL spectra were measured at certain time moments. As one can see in Figure $3 b$, the observed photobleaching dynamics are identical for both samples. The results of comparative analysis of time-resolved PL and photobleaching behavior are in good agreement with the other optical properties described above. All these experimental data strongly emphasize the similarity of the products obtained during the reactions between sodium citrate and organic amines, which of course includes the sample containing APTMS (the Si-containing amine) and the silicon-free sample that only has $n$-propylamine.

Thus, we can conclude with some certainty that silicon is not responsible for the optical properties of the obtained reaction products. Of course, $\mathrm{Si}$ atoms could be introduced into the structure of the $\left(\mathrm{Na}_{3} \mathrm{Cit}+\mathrm{APTMS}\right)$ reaction product, but their impact on the resulting optical properties is negligible. Considering the experiments described earlier, as well as taking into account the general chemical properties of silicon, it seems reasonable to assume that the formation of $\mathrm{Si}$ NPs (with a $\mathrm{Si}^{0}$ crystalline core) under the hydrothermal conditions of ref 1 seems rather doubtful and improbable.

As for the data of Zhong et al. as it pertains to the optical properties, the observations may be simply attributed to organic carbon-containing particles and/or molecular fluorophores formed as a result of multiple chemical transformations (predominantly, condensation reactions). Indeed, the PL properties reported by Zhong et al. are similar to those of different carbon nanoparticles and organic dyes. Furthermore, numerous papers devoted to the synthesis of photoluminescent carbon nanoparticles from different aminocontaining silanes (e.g., APTMS, APTES, etc.) and miscellaneous organic compounds (e.g., polybasic carboxylic acids, carbohydrates, etc.) have been published. ${ }^{59-61}$ According to the described findings, the aminosilane serves as the nitrogen source and as the surface modifier. Thus, the obtained carbon nanoparticles have alkoxysilane-covered surfaces and could be involved in further transformations.

Finally, according to the literature, citrate or citric acid reacts with amine-containing compounds under elevated temperature with formation of brightly luminescent products. ${ }^{60-72}$ Their chemical structures are very diverse, changing dramatically upon synthesis conditions. Particularly, the reaction of citric acid with ethanolamine ${ }^{72}$ or ethylenediamine ${ }^{73}$ under hydrothermal treatment results in the formation of either brightly luminescent molecular compounds of well-defined structure or small noncrystalline carbon-based nanoparticles. The particles of this type could be prepared from different molecular precursors using thermal, hydrothermal, or solvothermal routes (see comprehensive reviews ${ }^{74,75}$ ). Thus, the most acceptable statement is that the reaction of citrate with APTMS and n- 
$\mathrm{C}_{3} \mathrm{H}_{7} \mathrm{NH}_{2}$ under hydrothermal conditions leads to formation of carbon-based nanoparticles and/or molecular fluorophores.

In conclusion, the perfect similarity of the optical properties of the chemical products obtained in the reactions between sodium citrate and organic amines (Si-containing APTMS and Si-free $n$-propylamine) ferments doubt that the results can be attributed to Si NPs. Proof of Si NPs formation, delivered by Zhong et al., is insufficient for them to be confident in their conclusions. Indeed, formation of $\mathrm{Si}$ nanocrystallites in the hydrothermal conditions used by Zhong et al. (especially with the relatively low energy budget) is rather improbable from all viewpoints, including a chemical standpoint. One of the most important goals of this article is to prevent a huge wave of misinterpretations caused by the article of Zhong et al. However, the remarkable photoluminescent properties of the synthesized chemical species may provide access to useful organic carbon-containing particles that can be successfully used for numerous interdisciplinary applications.

\section{ASSOCIATED CONTENT}

\section{S Supporting Information}

The Supporting Information is available free of charge on the ACS Publications website at DOI: 10.1021/acs.chemmater.9b01067.

Synthesis details (PDF)

\section{AUTHOR INFORMATION}

Corresponding Author

*(B.V.O.) E-mail: oliinykb@gmail.com.

ORCID $\odot$

Bohdan V. Oliinyk: 0000-0002-1895-3980

Sergei Alekseev: 0000-0003-4190-8528

\section{Author Contributions}

B.V.O., D.M.K., S.A., and V.L. contributed equally to this work. Notes

The authors declare no competing financial interest.

\section{ACKNOWLEDGMENTS}

This research work was carried out in the framework of the CARTHER project (Proposal No. 690945) of the Marie Skłodowska-Curie Research and Innovation Staff Exchange program (Horizon 2020 Framework Programme). The European Commission is acknowledged for financial support.

\section{REFERENCES}

(1) Zhong, Y.; Peng, F.; Bao, F.; Wang, S.; Ji, X.; Yang, L.; Su, Y.; Lee, S. T.; He, Y. Large-Scale Aqueous Synthesis of Fluorescent and Biocompatible Silicon Nanoparticles and Their Use as Highly Photostable Biological Probes. J. Am. Chem. Soc. 2013, 135 (22), $8350-8356$.

(2) Alivisatos, A. P. Perspectives on the Physical Chemistry of Semiconductor Nanocrystals. J. Phys. Chem. 1996, 100 (31), 1322613239.

(3) Dasog, M.; Kehrle, J.; Rieger, B.; Veinot, J. G. C. Silicon Nanocrystals and Silicon-Polymer Hybrids: Synthesis, Surface Engineering, and Applications. Angew. Chem., Int. Ed. 2016, 55, 2322-2339.

(4) Qiu, M.; Singh, A.; Wang, D.; Qu, J.; Swihart, M.; Zhang, H.; Prasad, P. N. Biocompatible and Biodegradable Inorganic Nanostructures for Nanomedicine: Silicon and Black Phosphorus. Nano Today 2019, 25, 135-155.
(5) Erogbogbo, F.; Yong, K. T.; Roy, I.; Xu, G. X.; Prasad, P. N.; Swihart, M. T. Biocompatible Luminescent Silicon Quantum Dots for Imaging of Cancer Cells. ACS Nano 2008, 2 (5), 873-878.

(6) Montalti, M.; Cantelli, A.; Battistelli, G. Nanodiamonds and Silicon Quantum Dots: Ultrastable and Biocompatible Luminescent Nanoprobes for Long-Term Bioimaging. Chem. Soc. Rev. 2015, 44 (14), 4853-4921.

(7) Hussain, S.; Joo, J.; Kang, J.; Kim, B.; Braun, G. B.; She, Z.-G.; Kim, D.; Mann, A. P.; Mölder, T.; Teesalu, T.; et al. AntibioticLoaded Nanoparticles Targeted to the Site of Infection Enhance Antibacterial Efficacy. Nat. Biomed. Eng. 2018, 2 (2), 95-103.

(8) Beckman, J.; Ischenko, A. Silicon Nanoparticlefor Photodynamic Cancer Treatment Utilizing Quantum Dot Optical Properties. US2013/0337069A1, 2013.

(9) Gonzalez, C. M.; Veinot, J. G. C. Silicon Nanocrystals for the Development of Sensing Platforms. J. Mater. Chem. C 2016, 4 (22), 4836-4846.

(10) Aghajamali, M.; Xie, H.; Javadi, M.; Kalisvaart, W. P.; Buriak, J. M.; Veinot, J. G. C. Size and Surface Effects of Silicon Nanocrystals in Graphene Aerogel Composite Anodes for Lithium Ion Batteries. Chem. Mater. 2018, 30 (21), 7782-7792.

(11) Meinardi, F.; Ehrenberg, S.; Dhamo, L.; Carulli, F.; Mauri, M.; Bruni, F.; Simonutti, R.; Kortshagen, U.; Brovelli, S. Highly Efficient Luminescent Solar Concentrators Based on Earth-Abundant IndirectBandgap Silicon Quantum Dots. Nat. Photonics 2017, 11 (3), 177185.

(12) De Marco, M. L.; Semlali, S.; Korgel, B. A.; Barois, P.; Drisko, G. L.; Aymonier, C. Silicon-Based Dielectric Metamaterials: Focus on the Current Synthetic Challenges. Angew. Chem., Int. Ed. 2018, 57 (17), 4478-4498.

(13) Cheng, X.; Lowe, S. B.; Reece, P. J.; Gooding, J. J. Colloidal Silicon Quantum Dots: From Preparation to the Modification of SelfAssembled Monolayers (SAMs) for Bio-Applications. Chem. Soc. Rev. 2014, 43 (8), 2680-2700.

(14) Chang, H.; Sun, S. Q. Silicon Nanoparticles: Preparation, Properties, and Applications. Chin. Phys. B 2014, 23 (8), 088102088114.

(15) Ban, R.; Zheng, F.; Zhang, J. A Highly Sensitive Fluorescence Assay for 2,4,6-Trinitrotoluene Using Amine-Capped Silicon Quantum Dots as a Probe. Anal. Methods 2015, 7 (5), 1732-1737.

(16) Ji, X.; Peng, F.; Zhong, Y.; Su, Y.; Jiang, X.; Song, C.; Yang, L.; Chu, B.; Lee, S. T.; He, Y. Highly Fluorescent, Photostable, and Ultrasmall Silicon Drug Nanocarriers for Long-Term Tumor Cell Tracking and in-Vivo Cancer Therapy. Adv. Mater. 2015, 27 (6), 1029-1034.

(17) Zhong, Y.; Sun, X.; Wang, S.; Peng, F.; Bao, F.; Su, Y.; Li, Y.; Lee, S. T.; He, Y. Facile, Large-Quantity Synthesis of Stable, TunableColor Silicon Nanoparticles and Their Application for Long-Term Cellular Imaging. ACS Nano 2015, 9 (6), 5958-5967.

(18) Feng, Y.; Liu, Y.; Su, C.; Ji, X.; He, Z. New Fluorescent PH Sensor Based on Label-Free Silicon Nanodots. Sens. Actuators, B 2014, 203, 795-801.

(19) Song, B.; Zhong, Y.; Wu, S.; Chu, B.; Su, Y.; He, Y. OneDimensional Fluorescent Silicon Nanorods Featuring Ultrahigh Photostability, Favorable Biocompatibility, and Excitation Wavelength-Dependent Emission Spectra. J. Am. Chem. Soc. 2016, 138 (14), 4824-4831.

(20) Zhao, Q.; Zhang, R.; Ye, D.; Zhang, S.; Chen, H.; Kong, J. Ratiometric Fluorescent Silicon Quantum Dots-Ce6 Complex Probe for the Live Cell Imaging of Highly Reactive Oxygen Species. ACS Appl. Mater. Interfaces 2017, 9 (3), 2052-2058.

(21) Geng, X.; Li, Z.; Hu, Y.; Liu, H.; Sun, Y.; Meng, H.; Wang, Y.; $\mathrm{Qu}$, L.; Lin, Y. One-Pot Green Synthesis of Ultrabright N-Doped Fluorescent Silicon Nanoparticles for Cellular Imaging by Using Ethylenediaminetetraacetic Acid Disodium Salt as an Effective Reductant. ACS Appl. Mater. Interfaces 2018, 10 (33), 27979-27986.

(22) Li, S.; Wang, F.; He, X.-W.; Li, W.-Y.; Zhang, Y.-K. One-Pot Hydrothermal Preparation of Gadolinium-Doped Silicon Nanoparticles as a Dual-Modal Probe for Multicolor Fluorescence and 
Magnetic Resonance Imaging. J. Mater. Chem. B 2018, 6 (20), 33583365.

(23) Luo, L.; Song, Y.; Zhu, C.; Fu, S.; Shi, Q.; Sun, Y.-M.; Jia, B.; Du, D.; Xu, Z.-L.; Lin, Y. Fluorescent Silicon Nanoparticles-Based Ratiometric Fluorescence Immunoassay for Sensitive Detection of Ethyl Carbamate in Red Wine. Sens. Actuators, B 2018, 255, 27422749.

(24) Sharma, B.; Tanwar, S.; Sen, T. One Pot Green Synthesis of Si Quantum Dots and Catalytic Au Nanoparticle-Si Quantum Dot Nanocomposite. ACS Sustainable Chem. Eng. 2019, 7 (3), 33093318.

(25) Bose, S.; Ganayee, M. A.; Mondal, B.; Baidya, A.; Chennu, S.; Mohanty, J. S.; Pradeep, T. Synthesis of Silicon Nanoparticles from Rice Husk and Their Use as Sustainable Fluorophores for White Light Emission. ACS Sustainable Chem. Eng. 2018, 6 (5), 6203-6210.

(26) Dou, Y.-K.; Chen, Y.; He, X.-W.; Li, W.-Y.; Li, Y.-H.; Zhang, Y.K. Synthesis of Water-Dispersible Mn 2+ Functionalized Silicon Nanoparticles under Room Temperature and Atmospheric Pressure for Fluorescence and Magnetic Resonance Dual-Modality Imaging. Anal. Chem. 2017, 89 (21), 11286-11292.

(27) Wang, J.; Ye, D.-X.; Liang, G.-H.; Chang, J.; Kong, J.-L.; Chen, J.-Y. One-Step Synthesis of Water-Dispersible Silicon Nanoparticles and Their Use in Fluorescence Lifetime Imaging of Living Cells. J. Mater. Chem. B 2014, 2 (27), 4338-4345.

(28) Han, Y.; Chen, Y.; Feng, J.; Liu, J.; Ma, S.; Chen, X. One-Pot Synthesis of Fluorescent Silicon Nanoparticles for Sensitive and Selective Determination of 2,4,6-Trinitrophenol in Aqueous Solution. Anal. Chem. 2017, 89 (5), 3001-3008.

(29) Ye, H.-L.; Cai, S.-J.; Li, S.; He, X.-W.; Li, W.-Y.; Li, Y.-H.; Zhang, Y.-K. One-Pot Microwave Synthesis of Water-Dispersible, High Fluorescence Silicon Nanoparticles and Their Imaging Applications in Vitro and in Vivo. Anal. Chem. 2016, 88 (23), 11631-11638.

(30) Ma, S.; Chen, Y.; Feng, J.; Liu, J.; Zuo, X.; Chen, X. One-Step Synthesis of Water-Dispersible and Biocompatible Silicon Nanoparticles for Selective Heparin Sensing and Cell Imaging. Anal. Chem. 2016, 88 (21), 10474-10481.

(31) Ma, S.; Yue, T.; Xiao, X.; Cheng, H.; Zhao, D. A Proof of Concept Study of Preparing Ultra Bright Silicon Quantum Dots Based on Synergistic Effect of Reductants. J. Lumin. 2018, 201 (April), 77-84.

(32) Han, Y.; Chen, Y.; Liu, J.; Niu, X.; Ma, Y.; Ma, S.; Chen, X. Room-Temperature Synthesis of Yellow-Emitting Fluorescent Silicon Nanoparticles for Sensitive and Selective Determination of Crystal Violet in Fish Tissues. Sens. Actuators, B 2018, 263, 508-516.

(33) Wu, C.; Peng, X.; Lu, Q.; Li, H.; Zhang, Y.; Yao, S. Ultrasensitive Silicon Nanoparticle Ratiometric Fluorescence Determination of Mercury(II). Anal. Lett. 2018, 51 (7), 1013-1028.

(34) Zhong, Y.; Song, B.; Shen, X.; Guo, D.; He, Y. Fluorescein Sodium Ligand-Modified Silicon Nanoparticles Produce Ultrahigh Fluorescence with Robust PH- and Photo-Stability. Chem. Commun. 2019, 55 (3), 365-368.

(35) Hu, G.; Sun, Y.; Xie, Y.; Wu, S.; Zhang, X.; Zhuang, J.; Hu, C.; Lei, B.; Liu, Y. Synthesis of Silicon Quantum Dots with Highly Efficient Full-Band UV Absorption and Their Applications in Antiyellowing and Resistance of Photodegradation. ACS Appl. Mater. Interfaces 2019, 11 (6), 6634-6643.

(36) Han, Y.; Chen, Y.; Feng, J.; Na, M.; Liu, J.; Ma, Y.; Ma, S.; Chen, X. Investigation of Nitrogen Content Effect in Reducing Agent to Prepare Wavelength Controllable Fluorescent Silicon Nanoparticles and Its Application in Detection of 2-Nitrophenol. Talanta 2019, 194, 822-829.

(37) Shen, X.-B.; Song, B.; Fang, B.; Yuan, X.; Li, Y.-Y.; Wang, S.-Y.; Ji, S.-J.; He, Y. Solvent Polarity-Induced Photoluminescence Enhancement (SPIPE): A Method Enables Several-Fold Increase in Quantum Yield of Silicon Nanoparticles. Nano Res. 2019, 12 (2), 315-322.

(38) Zhang, J.; Yu, S. H. Highly Photoluminescent Silicon Nanocrystals for Rapid, Label-Free and Recyclable Detection of Mercuric Ions. Nanoscale 2014, 6 (8), 4096-4101.
(39) Li, Q.; Peng, K.; Yu, Y.; Ruan, X.; Wei, Y. One-Pot Synthesis of Highly Fluorescent Silicon Nanoparticles for Sensitive and Selective Detection of Hemoglobin. Electrophoresis 2019, DOI: 10.1002/ elps.201900023.

(40) Xiao, F.; Xiao, Y.; Chen, F.; Liu, X.; Lin, C.; Chen, J.; Wu, Y. Facile Synthesis of Silicon Quantum Dot-Gadolinium: A Potential Fluorescent/T1-T2Multimodal Imaging Agent. Talanta 2019, 199, 336-346.

(41) Roy, D.; Fouzder, C.; Mukhuty, A.; Pal, S.; Mondal, M. K.; Kundu, R.; Chowdhury, P. Designed Synthesis of Dual Emitting Silicon Quantum Dot for Cell Imaging: Direct Labeling of Alpha 2HS-Glycoprotein. Bioconjugate Chem. 2019, 30 (5), 1575-1583.

(42) Liu, L.; Zhu, G.; Zeng, W.; Yi, Y.; Lv, B.; Qian, J.; Zhang, D. Silicon Quantum Dot-Coated onto Gold Nanoparticles as an Optical Probe for Colorimetric and Fluorometric Determination of Cysteine. Microchim. Acta 2019, 186 (2), 98.

(43) Zheng, X.; Zhang, D.; Fan, Z.; Huang, Z.; Mao, H.; Ma, Y. One-Step Hydrothermal Synthesis of Ultrabright Water-Soluble Silicon Nanoparticles for Folate-Receptor-Mediated Bioimaging. J. Mater. Sci. 2019, 54 (13), 9707-9717.

(44) Song, B.; He, Y. Fluorescent Silicon Nanomaterials: From Synthesis to Functionalization and Application. Nano Today 2019, 26, $149-163$.

(45) Zhong, Y.; Chu, B.; Bo, X.; He, Y.; Zhao, C. Aqueous Synthesis of Three-Dimensional Fluorescent Silicon-Based Nanoscale Networks Featuring Unusual Anti-Photobleaching Properties. Chem. Commun. 2019, 55 (5), 652-655.

(46) Campos, B. B.; Algarra, M.; Alonso, B.; Casado, C. M.; Jiménez-Jiménez, J.; Rodríguez-Castellón, E.; Esteves Da Silva, J. C. G. Fluorescent Sensor for Cr(VI) Based in Functionalized Silicon Quantum Dots with Dendrimers. Talanta 2015, 144 (Vi), 862-867.

(47) Song, C.; Zhong, Y.; Jiang, X.; Peng, F.; Lu, Y.; Ji, X.; Su, Y.; He, Y. Peptide-Conjugated Fluorescent Silicon Nanoparticles Enabling Simultaneous Tracking and Specific Destruction of Cancer Cells. Anal. Chem. 2015, 87 (13), 6718-6723.

(48) Wu, J.; Dai, J.; Shao, Y.; Sun, Y. One-Step Synthesis of Fluorescent Silicon Quantum Dots (Si-QDs) and Their Application for Cell Imaging. RSC Adv. 2015, 5 (102), 83581-83587.

(49) Wu, S.; Zhong, Y.; Zhou, Y.; Song, B.; Chu, B.; Ji, X.; Wu, Y.; $\mathrm{Su}$, Y.; He, Y. Biomimetic Preparation and Dual-Color Bioimaging of Fluorescent Silicon Nanoparticles. J. Am. Chem. Soc. 2015, 137 (46), $14726-14732$.

(50) Yang, L.; Liu, Y.; Zhong, Y. L.; Jiang, X. X.; Song, B.; Ji, X. Y.; Su, Y. Y.; Liao, L. S.; He, Y. Fluorescent Silicon Nanoparticles Utilized as Stable Color Converters for White Light-Emitting Diodes. Appl. Phys. Lett. 2015, 106 (17), 173109.

(51) Zhang, X.; Chen, X.; Kai, S.; Wang, H. Y.; Yang, J.; Wu, F. G.; Chen, Z. Highly Sensitive and Selective Detection of Dopamine Using One-Pot Synthesized Highly Photoluminescent Silicon Nanoparticles. Anal. Chem. 2015, 87 (6), 3360-3365.

(52) Jutzi, P.; Schubert, U. Silicon Chemistry: From the Atom to Extended Systems; Jutzi, P., Schubert, U., Eds.; Wiley-VCH Verlag GmbH \& Co. KGaA: Weinheim, Germany, 2007; DOI: 10.1002/ 9783527610761.

(53) Lickiss, P. D. Silicon: Inorganic Chemistry. Encycl. Inorg. Bioinorg. Chem. 2011, 256 (1), 524-527.

(54) Sakurai, H. Silicon: Organosilicon Chemistry. In Encyclopedia of Inorganic and Bioinorganic Chemistry; Major Reference Works; John Wiley \& Sons, Ltd.: Chichester, UK, 2011; DOI: 10.1002/ 9781119951438.eibc0204.

(55) Mittemeijer, E. J.; Welzel, U. The 'State of the Art' of the Diffraction Analysis of Crystallite Size and Lattice. Strain. Zeitschrift fur Krist. 2008, 223 (9), 552-560.

(56) Holm, J.; Roberts, J. T. Thermally Induced Hydrosilylation at Deuterium-Terminated Silicon Nanoparticles: An Investigation of the Radical Chain Propagation Mechanism. Langmuir 2009, 25 (12), $7050-7056$.

(57) Thiessen, A. N.; Ha, M.; Hooper, R. W.; Yu, H.; Oliynyk, A. O.; Veinot, J. G. C.; Michaelis, V. K. Silicon Nanoparticles: Are They 
Crystalline from the Core to the Surface? Chem. Mater. 2019, 31 (3), 678-688.

(58) Murphy, C. J.; Buriak, J. M. Best Practices for the Reporting of Colloidal Inorganic Nanomaterials. Chem. Mater. 2015, 27, 49114913.

(59) Chen, P.-C.; Chen, Y.-N.; Hsu, P.-C.; Shih, C.-C.; Chang, H.-T. Photoluminescent Organosilane-Functionalized Carbon Dots as Temperature Probes. Chem. Commun. 2013, 49 (16), 1639.

(60) Xie, Z.; Wang, F.; Liu, C. Y. Organic-Inorganic Hybrid Functional Carbon Dot Gel Glasses. Adv. Mater. 2012, 24 (13), $1716-1721$.

(61) Mao, Y.; Bao, Y.; Han, D.; Li, F.; Niu, L. Efficient One-Pot Synthesis of Molecularly Imprinted Silica Nanospheres Embedded Carbon Dots for Fluorescent Dopamine Optosensing. Biosens. Bioelectron. 2012, 38 (1), 55-60.

(62) Dong, Y.; Pang, H.; Yang, H. B.; Guo, C.; Shao, J.; Chi, Y.; Li, C. M.; Yu, T. Carbon-Based Dots Co-Doped with Nitrogen and Sulfur for High Quantum Yield and Excitation-Independent Emission. Angew. Chem., Int. Ed. 2013, 52 (30), 7800-7804.

(63) Bourlinos, A. B.; Stassinopoulos, A.; Anglos, D.; Zboril, R.; Georgakilas, V.; Giannelis, E. P. Photoluminescent Carbogenic Dots. Chem. Mater. 2008, 20 (14), 4539-4541.

(64) Hou, J.; Yan, J.; Zhao, Q.; Li, Y.; Ding, H.; Ding, L. A Novel One-Pot Route for Large-Scale Preparation of Highly Photoluminescent Carbon Quantum Dots Powders. Nanoscale 2013, 5 (20), 9558-9561.

(65) Zong, J.; Zhu, Y.; Yang, X.; Shen, J.; Li, C. Synthesis of Photoluminescent Carbogenic Dots Using Mesoporous Silica Spheres as Nanoreactors. Chem. Commun. 2011, 47 (2), 764-766.

(66) Zhou, J.; Yang, Y.; Zhang, C. Y. A Low-Temperature SolidPhase Method to Synthesize Highly Fluorescent Carbon Nitride Dots with Tunable Emission. Chem. Commun. 2013, 49 (77), 8605-8607.

(67) Zhai, X.; Zhang, P.; Liu, C.; Bai, T.; Li, W.; Dai, L.; Liu, W. Highly Luminescent Carbon Nanodots by Microwave-Assisted Pyrolysis. Chem. Commun. 2012, 48 (64), 7955-7957.

(68) Yang, Z.; Xu, M.; Liu, Y.; He, F.; Gao, F.; Su, Y.; Wei, H.; Zhang, Y. Nitrogen-Doped, Carbon-Rich, Highly Photoluminescent Carbon Dots from Ammonium Citrate. Nanoscale 2014, 6 (3), 18901895.

(69) Shi, W.; Li, X.; Ma, H. A Tunable Ratiometric PH Sensor Based on Carbon Nanodots for the Quantitative Measurement of the Intracellular PH of Whole Cells. Angew. Chem., Int. Ed. 2012, 51 (26), 6432-6435.

(70) Qu, S.; Wang, X.; Lu, Q.; Liu, X.; Wang, L. A Biocompatible Fluorescent Ink Based on Water-Soluble Luminescent Carbon Nanodots. Angew. Chem., Int. Ed. 2012, 51 (49), 12215-12218.

(71) Qu, D.; Zheng, M.; Du, P.; Zhou, Y.; Zhang, L.; Li, D.; Tan, H.; Zhao, Z.; Xie, Z.; Sun, Z. Highly Luminescent S, N Co-Doped Graphene Quantum Dots with Broad Visible Absorption Bands for Visible Light Photocatalysts. Nanoscale 2013, 5 (24), 12272-12277.

(72) Krysmann, M. J.; Kelarakis, A.; Dallas, P.; Giannelis, E. P. Formation Mechanism of Carbogenic Nanoparticles with Dual Photoluminescence Emission. J. Am. Chem. Soc. 2012, 134 (2), 747-750.

(73) Song, Y.; Zhu, S.; Zhang, S.; Fu, Y.; Wang, L.; Zhao, X.; Yang, B. Investigation from Chemical Structure to Photoluminescent Mechanism: A Type of Carbon Dots from the Pyrolysis of Citric Acid and an Amine. J. Mater. Chem. C 2015, 3 (23), 5976-5984.

(74) Shamsipur, M.; Barati, A.; Karami, S. Long-Wavelength, Multicolor, and White-Light Emitting Carbon-Based Dots: Achievements Made, Challenges Remaining, and Applications. Carbon 2017, 124, 429-472.

(75) Chan, K. K.; Yap, S. H. K.; Yong, K.-T. Biogreen Synthesis of Carbon Dots for Biotechnology and Nanomedicine Applications. Nano-Micro Lett. 2018, 10 (4), 72.

\section{NOTE ADDED AFTER ASAP PUBLICATION}

The Supporting Information file was not present in the version of this paper published on the Web on July 21, 2019. The paper was reposted with the Supporting Information file on September 10, 2019. 